\title{
$\mathrm{FMICW}$ 와 버니어식 과정을 통한 정밀 빙붕 깊이 측정 레이다에 관한 연구
}

\section{High-Precision Measurement of Ice-Shelf Thickness Using Frequency-Modulated Interrupted Continuous Wave Method and Vernier-like Process}

\author{
이 영 재·신 승 하* 김 은 희 \\ Young-Jae Lee $\cdot$ Seung-Ha Shin* $\cdot$ Eun Hee Kim
}

요 약

최근 지구 온난화를 예측하는 방법으로써 레이다를 이용한 빙붕의 두께 측정에 대한 연구가 진행되고 있다. 기존에 개발된 레이다는 $\mathrm{FMCW}$ 방식의 파형을 사용하여 주파수에 의한 대략 거리와 위상에 의한 세밀 거리를 특정하였으며, 이로부터 연간 밀리미터 수준의 두께 변화를 측정하는 것이 가능하다. 그러나 이러한 연속파는 수신 파워의 차이가 큰 표면 반사 신호와 바닥 반사 신호가 동시에 수신되므로 수신기에 요구되는 동적 범위가 크다. 본 논문은 이를 개선하기 위한 펄스를 사용하는 FMICW 방식을 제안하고, 시뮬레이션을 통해 성능을 보였다. 제안된 방법은 동일 피크 파워에 대해 SNR을 감소시킬 수 있으나, 거리에 따른 이득조정이 가능하고, 최소 탐지거리를 조정할 수 있는 장점을 가진다.

\section{Abstract}

A radar system has been developed to predict global warming by measuring ice-shelf thicknesses. This system uses a frequencymodulated continuous-wave(FMCW) waveform and phase-sensitive method through the so-called Vernier-like process, which measures the target range by adding the fine range from the phase information to the rough range from the frequency. However, the continuous waves require a large dynamic range of the receiver because short-range and long-range reflection signals are received simultaneously. To improve this, we propose a frequency-modulated interrupted continuous wave(FMICW) method and demonstrate its performance through simulation. Although the proposed method reduces the signal-to-noise ratio(SNR) based on the same peak power, the gain can be adjusted according to the range, and the minimum detection range can be controlled.

Key words: FMICW, Phase Sensitive Detection, Depth Measurement

$$
\text { I. 서 론 }
$$

지구 온난화로 인한 기후의 변화는 심각한 환경 문제
로 대두되고 있다. 온난화가 지속되면 빙하가 녹게 되고, 해수면 상승과 각종 생태계 문제를 일으키게 되며, 빙하 가 대기로 반사시키던 열을 지구가 흡수하게 되어 온난

「이 연구는 2018년도 국내 산 · 연 극지 공동연구프로그램 사업 연구비 지원으로 연구되었음(PE18910, 극지 빙하구조 분석 레이다 국산화 개발).」 세종대학교 국방시스템공학과(Department of Defense Systems Engineering, Sejong University)

*(주)유텔(U-Tel. Co., LTD.)

- Manuscript received October 15, 2019 ; Revised December 10, 2019 ; Accepted December 24, 2019. (ID No. 20191015-101)

· Corresponding Author: Eun Hee Kim (e-mail: eunheekim@sejong.ac.kr) 
화 현상이 가속화 될 수도 있다.

빙붕(ice shelf)은 빙상(ice sheet)인 남극대륙과 이어져 있는 바다 위에 떠있는 얼음 덩어리를 뜻한다. 바다에 떠 있기는 하나, 남극대륙과 연결되어 있어 얼음이 계속 공 급되기 때문에 전체적인 크기를 유지하는 것으로 알려 져 있다. 빙붕은 남극 대륙으로 접근하는 따뜻한 물의 흐 름을 막아 남극대륙을 유지하는 역할을 하며, 반대로 대 륙의 빙하가 바다로 해양으로 유입되는 것을 막아 해수 면의 상승을 억제하는 역할을 한다. 최근 이러한 빙붕의 두께가 앏아지거나 붕괴되는 모습이 여러 차례 관측되 고 있는데, 이는 지구 온난화 때문으로 해석된다. 따라서 이러한 빙붕의 두께 변화를 측정하여 해수면의 상승 등 미래 기후 변화를 예측하고자 하는 연구들이 진행되고 있다 ${ }^{[1]}$.

영국에서 두께 변화를 $\mathrm{mm} / \mathrm{year}$ 의 정밀도로 측정하기 위해 위상감지 얼음 투과 레이다, pRES(phase sensitive Radio-Echo Sounder)를 개발하였다 ${ }^{[2]}$. 이 시스템은 유전율 의 갑작스러운 변화에 의해 얼음 바닥(ice base) 또는 내층 에서 반사되는 레이다 신호를 탐지하도록 하였다. UHF대 역의 FMCW(Frequency Modulated Continuous Wave) 방식 파형을 사용하였으며, 남극 대륙의 조지(George) VI 빙붕 과 로니(Ronne) 빙붕 위의 여러 위치에서 바닥층(basal layer)과 내부 층의 깊이를 성공적으로 측정하였다 ${ }^{[2]}$. 그 러나 pRES 장비는 범용 네트워크 분석기로 이루어져 부 피가 크고, 수신기 잡음지수가 매우 높으며, 전력 소비량 도 클 뿐 아니라, 저온에서의 장시간 작동에 한계를 가지 고 있어 이를 보완하기 위한 시스템 개발이 수행되고 있 다 ${ }^{[3] \sim[5]}$.

$\mathrm{pRES}$ 에서 사용한 FMCW 방식은 선형적 주파수 변조 된 연속파를 사용하고, 송신 신호와 수신신호를 주파수 차이를 이용하여 표적의 거리를 측정한다. 이 방식은 하드 웨어 및 신호처리가 다소 간단한 것에 비해 성능이 좋아 서 고도계, 차량용 레이다 등에 많이 사용되고 있담] [9].

레이다를 이용하여 빙붕의 두께를 측정하는 경우, 반사 신호는 주로 표면에서와 바닥 층에서 발생하며, 수신 신호 의 파워 차이로 인해 요구되는 수신기의 동적 범위가 매우 크다. 본 논문은 이를 보상하는 방법으로 FMICW(Frequency Modulated Interrupted Continuous Wave)를 사용하는 방법을
제안하고, 시뮬레이션을 통해 개선된 결과를 제시하였다.

본 논문의 구성은 다음과 같다. 2장에서는 $\mathrm{FMCW}$ 를 이 용한 기존의 빙붕 두께 측정방법을 정리하고, 수신기에 요구되는 동적 범위를 제시하였다. 3 장에서는 수신기의 동적 범위를 개선하기 위해 제안된 FMICW 방식을 기술하 였으며, 수식과 몬테카를로 시뮬레이션을 통해 개선된 성 능을 제시하였다. 마지막으로 4장에 결론을 정리하였다.

\section{FMCW 방식을 사용한 거리측정 방법}

일반적으로 FMCW 방식의 레이다에서 송신신호와 수 신신호의 주파수 차이는 표적 속도에 의한 도플러 천이 와 거리에 의한 주파수 차이의 합으로 나타나지만, 빙붕 측정에서의 표적은 정지해 있으므로 두 신호의 차이는 거리에 의해서만 나타난다.

FMCW radar에서 송신주파수는 다음과 같이 표현할 수 있다.

$$
\omega_{t}(t)=\omega_{c}+K\left(t-\frac{T}{2}\right), 0 \leq t \leq T, K=2 \pi \frac{B}{T}
$$

여기서 $T$ 는 송신 주기이고, $B$ 는 대역폭이다. 주파수 $\omega_{t}(t)$ 로 얻어지는 송신 위상 $\phi_{t}(t)$ 와 수신되는 위상 $\phi_{r}(t)$ 는 다음과 같다.

$$
\begin{aligned}
\phi_{t}(t) & =\int \omega_{t}(t) d t=\omega_{c} t+\frac{K}{2}\left(t-\frac{T}{2}\right)^{2}+\phi_{0} \\
\phi_{r}(t) & =\phi_{r}(t-\tau) \\
& =\omega_{c}(t-\tau)+\frac{K}{2}\left(t-\frac{T}{2}-\tau\right)^{2}+\phi_{0}
\end{aligned}
$$

기저대역의 수신 신호의 위상은 송수신 신호의 위상 차이 $\phi_{d}(t)$ 로 나타나며, 아래와 같이 표현할 수 있다.

$\phi_{d}(t)=\phi_{t}(t)-\phi_{r}(t)=\omega_{c} \tau+K \tau\left(t-\frac{T}{2}\right)-\frac{K \tau^{2}}{2}$

여기서 $\omega_{c}=2 \pi f_{c}, \tau=2 R \sqrt{\varepsilon_{r}} / c, c$ 는 광속, $\varepsilon_{r}$ 은 얼음의 유전 상수이다. 위상을 $T / 2$ 만큼 역지연시키면,

$\phi_{d}\left(t+\frac{T}{2}\right)=\omega_{c} \tau+K \tau t-\frac{K \tau^{2}}{2}$

가 된다. 일반적으로 $\mathrm{FMCW}$ 방식에서 거리는 식 (5)의 두 
번째 항인 주파수 $(\Delta f=K \tau / 2 \pi)$ 로부터 다음과 같이 검출 한다.

$R_{\text {coarse }}=\Delta f \cdot \frac{T}{B} \cdot \frac{c}{2 \sqrt{\varepsilon_{r}}}$

이 때 거리의 해상도는 대역폭에 의해 결정된다. 그러 나, 이는 빙붕의 두께 측정에 요구되는 $\mathrm{mm}$ 급 정확도에 미치지 못하므로, 세 번째 항인 위상을 이용하여 추가 정 밀도를 확보하여야 한다. 따라서 측정 거리는 식 (6)에서 계산된 거리에 위상에 의한 정밀 거리를 더하여 아래와 같이 구한다.

$$
\begin{aligned}
R & =R_{\text {coarse }}+R_{\text {fine }} \\
& =\tau \cdot \frac{c}{2 \sqrt{\varepsilon_{r}}}=\left(\tau_{\text {coarse }}+\tau_{\text {fine }}\right) \cdot \frac{c}{2 \sqrt{\varepsilon_{r}}}
\end{aligned}
$$

여기서 $\tau$ 는 지연 시간이다.

식 (5)에서 $t=0$ 일 때 초기 위상 $\phi$ 은

$$
\begin{aligned}
\phi & =\phi_{d}\left(\frac{T}{2}\right)=\omega_{c} \tau-\frac{K \tau^{2}}{2} \\
& =\omega_{c}\left(\tau_{\text {coarse }}+\tau_{\text {fine }}\right)-\frac{K\left(\tau_{\text {coarse }}+\tau_{\text {fine }}\right)^{2}}{2} \\
& \simeq \omega_{c}\left(\tau_{\text {coarse }}+\tau_{\text {fine }}\right)-\frac{K\left(\tau_{\text {coarse }}\right)^{2}}{2}
\end{aligned}
$$

이므로, 측정된 위상으로부터 세부거리 $R_{f i n e}$ 은 다음과 같이 구할 수 있다.

$$
\begin{aligned}
R_{\text {fine }} & =\frac{c}{2 \omega_{c}}\left[\phi-\omega_{c} \tau_{\text {coar se }}+\frac{K\left(\tau_{\text {coarse }}\right)^{2}}{2}\right] \\
& =\frac{c}{2 \omega_{c}} \Delta \phi=\frac{\lambda}{4 \pi} \Delta \phi
\end{aligned}
$$

여기서 $\lambda$ 는 파장이다. 즉, $R_{f i n e}$ 에 의하여 파장보다 짧은 상 세 거리를 구하고, 식 $(5)$ 에서 구한 대략 거리 $\left(R_{\text {coarse }}\right)$ 에 더 하여 최종 거리를 측정한다. 이러한 방식으로 거리 측정치 를 구하는 것을 Vernier-like process라고 하며, 이렇게 측정된 거리는 최적 방법에 의해 측정될 수 있는 $\mathrm{rms}(\mathrm{root}$ mean square) 거리오차의 수학적 최솟값인 크래머-라오 한계치 (Crammer-Rao bound)에 이르며, 다음과 같이 표현된다.

$$
R_{\text {error }, C R}=\frac{\lambda}{4 \pi \sqrt{2 S N R}}
$$

그림 1에서 제시된 과정에 따라 반사 신호를 모의하여 거리에 따른 측정 정확도를 몬테카를로 시뮬레이션으로 수행한 결과, 그림 2에서 나타낸 바와 같이 측정된 $\mathrm{rms}$ 거 리 오차가 이론치와 같음을 알 수 있다. 시뮬레이션에 사 용된 변수들은 표 1 에 정리되어 있으며, 노이즈는 가우시 언 분포로 가정하였고, 몬테카를로 시뮬레이션은 각 거리 에 대하여 각 1,000 회 실시하였다.

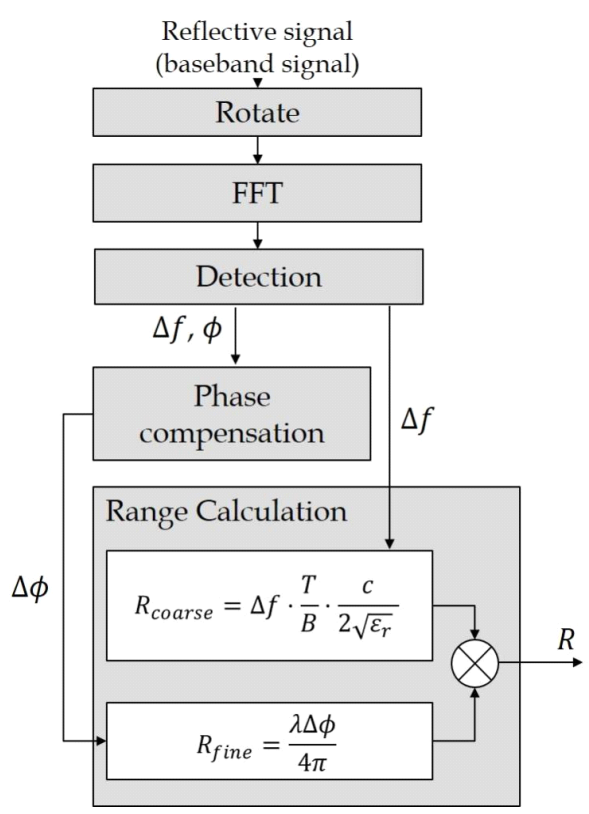

그림 1. 위상 검출 $\mathrm{FMCW}$ 레이다 신호처리 Fig. 1. Summary of phase sensitive FMCW process.

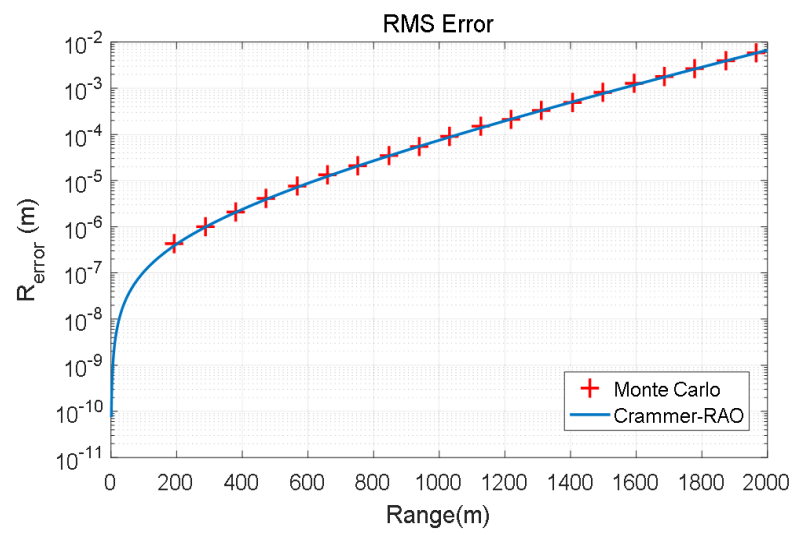

그림 2. 거리에 따른 RMS 거리 오차

Fig. 2. RMS error according to the range. 
표 1. 시뮬레이션에 사용된 변수들

Table 1. Simulation parameters.

\begin{tabular}{|c|c|}
\hline Parameter & Value (unit) \\
\hline Operating frequency, $f_{c}$ & $300(\mathrm{MHz})$ \\
\hline Sweep bandwidth, $B$ & $200(\mathrm{MHz})$ \\
\hline RF power, $P_{t}$ & $20(\mathrm{dBm})$ \\
\hline Antenna gains, $G_{t,} G_{r}$ & $10(\mathrm{dBi})$ \\
\hline Noise figure, $N$ & $6(\mathrm{~dB})$ \\
\hline Pulse duration, $T$ & $1(\mathrm{~s})$ \\
\hline ADC sampling rate & $24(\mathrm{ksamples} / \mathrm{s})$ \\
\hline Path loss, $L$ & $0.015(\mathrm{~dB} / \mathrm{m})$ \\
\hline Reflection coefficient, $\rho$ & $-2(\mathrm{~dB})$ \\
\hline
\end{tabular}

참고문헌 [3]으로부터 수신 파워는 다음과 같이 표현 된다.

$$
P_{r}=\frac{P_{t} G_{r} G_{t} \rho L \lambda^{2}}{16 \pi R^{3}} \cdot \frac{c}{2 B \sqrt{\varepsilon_{r}}}
$$

여기서 $L$ 은 경로 손실로 거리에 따라 늘어나며, $\rho$ 는 반사 계수이다. 거리에 따른 수신 파워는 그림 3 과 같다.

빙붕의 두께를 측정하는 경우, 레이다 신호의 반사는 표면에서와 약 $2 \mathrm{~km}$ 근처의 바닥 층에서 발생하므로, 수 신기에 요구되는 동적 범위는 $160(\mathrm{~dB})$ 이상이 된다. 이는 실 제작에 어려움이 있으므로 본 논문에서는 $\mathrm{FMICW}$ (Frequency Modulated Interrupted CW) 파형을 통해 동적

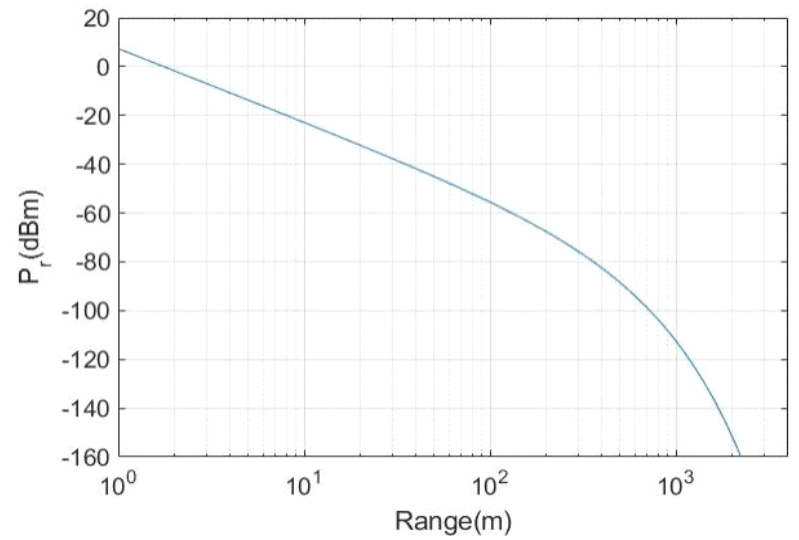

그림 3. 표적 거리에 따른 수신 신호의 파워

Fig. 3. Received power vs. range.
범위를 줄이는 것을 제안하였다. 제안된 $\mathrm{FMICW}$ 는 펄스 를 사용하므로 전체적으로 파워가 줄어들지만, 표면에서 의 반사 신호와 바닥 층에서의 반사 신호를 분리할 수 있 을 뿐 아니라, 수신구간 제한으로 표면 반사 파워를 없앨 수 있다. 예를 들어 $100 \mathrm{~m}$ 이하의 신호의 수신을 제한하 면 수신기의 동적 범위는 $100(\mathrm{~dB})$ 이하가 된다.

\section{FMIICW 방식을 사용한 거리측정 방법}

$\mathrm{FMICW}$ 는 $\mathrm{FMCW}$ 를 펄스로 끊어 송신하는 방식으로 그림 4의 과정으로 구성할 수 있다.

그림 5 에서와 같이 듀티 사이클을 $50 \%$ 로 사용하고 송 수신 구간을 분리하면, 송신펄스 길이 $\left(T_{s} / 2\right)$ 와 표적 거리 에 의한 반사 신호의 지연시간 $(\tau)$ 이 일치하는 경우, 송신 신호가 모두 수신될 수 있으나, 이보다 가깝거나 먼 신호 는 수신파워가 줄어들게 된다.

송신구간과 수신구간을 분리하는 것은 송신 신호에 의 한 영향을 줄여 수신 신호의 특성을 개선할 수 있고, 수신 구간을 변경하면, 최소 탐지 거리를 조정할 수 있다. 또한 단거리 표면 반사 신호와 바닥 층의 반사 신호가 시간 축 에서 분리되어 동시에 수신되지 않으므로 거리에 따라 게인을 조정하는 STC(Sensitivity Time Control ) 방식도 적

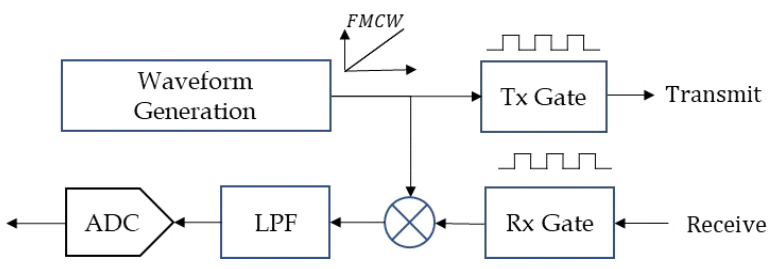

그림 4. FMICW 블록도

Fig. 4. FMICW block diagram.

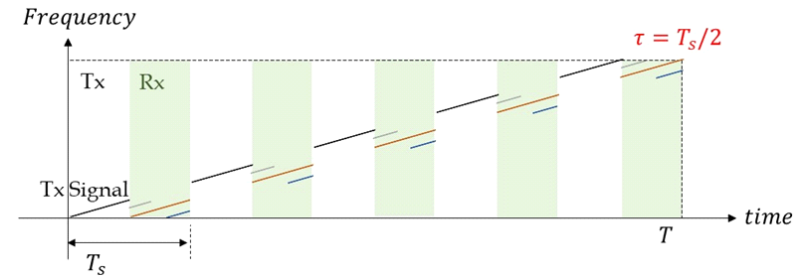

그림 5. FMICW 파형

Fig. 5. FMICW waveform. 
용이 가능하다.

펄스의 길이는 최대 탐지거리에서의 지연시간보다 짧 게 선정하여야 단거리 반사 신호와 수신신호를 분리할 수 있다. 즉,

$$
\Delta=\tau_{\max }-\frac{T_{s}}{2}>0
$$

본 논문에서는 최대 탐지거리 $2 \mathrm{~km}$ 에서 펄스 시간지연 이 $23.5 \mathrm{usec}$ 이므로, 펄스길이를 $20.5 \mathrm{usec}$ 로 사용하는 경 우, $255 \mathrm{~m}(3 \mathrm{usec})$ 이내의 반사 신호는 $2 \mathrm{~km}$ 의 반사 신호 와 분리 수신되며, 수신 구간을 조정하여 최소 탐지거리 를 제한할 수도 있다.

시뮬레이션에 사용된 FMICW는 주기가 $41.6 \mathrm{usec}(24$ $\mathrm{KHz}$ ), 듀티 사이클 0.5 인 펄스이며, 수신 필터의 입력인 노이즈의 파워는 수신구간의 듀티 사이클에 비례하며, 신 호의 파워는 수신되는 신호의 듀티 사이클의 제곱에 비 례하기 때문에 신호 대 노이즈 비(signal to noise ratio: SNR) 는 $\mathrm{FMCW}$ 를 사용했을 때와 비교하여 식 (14)와 같이 변 경된다 ${ }^{[3],[10]}$.

$$
\begin{aligned}
& S N R=\frac{P_{t} G_{r} G_{t} \rho L \lambda^{2}}{16 \pi R^{3}} \cdot \frac{c}{2 B \sqrt{\varepsilon_{r}}} \cdot \frac{T}{k T_{a} F} \\
& S N R_{\text {FMICW }}=S N R \times \frac{d_{r}^{2}}{d_{n}}
\end{aligned}
$$

여기서, $k$ 는 볼츠만 상수, $T_{a}$ 는 시스템의 온도, $F$ 는 잡음 지수(noise figure), $T$ 는 누적측정시간이다.

그림 6에서 보이는 바와 같이 식 (14)의 분모의 $d_{n}$ 은 수 신 구간의 듀티 사이클로 0.5 이며, $d_{r}$ 은 거리에 따른 수신 신호의 듀티 사이클로 식 (15)와 같이 표현될 수 있다.

$$
d_{r}= \begin{cases}R / 3540 & \text { if } 1770 \geq R>0 \\ 1-R / 3540 & \text { if } 3540>R>1770\end{cases}
$$

그림 7에는 거리에 따른 SNR을 비교하여 나타내었다. 표적 거리 $1,770 \mathrm{~m}(20.8 \mathrm{usec})$ 에서의 반사 신호는 모두 수 신되어 송신 신호가 줄어든 절반 $(3 \mathrm{~dB})$ 만큼 $\mathrm{SNR}$ 이 감소 하며, $2,000 \mathrm{~m}$ 에서는 $0.353(4.56 \mathrm{~dB})$ 감소한다. 펄스의 사 용으로 인한 가장 큰 단점은 파워 또는 SNR의 감소이며, 이는 누적시간 또는 송신 피크 파워의 증가에 의해 보상

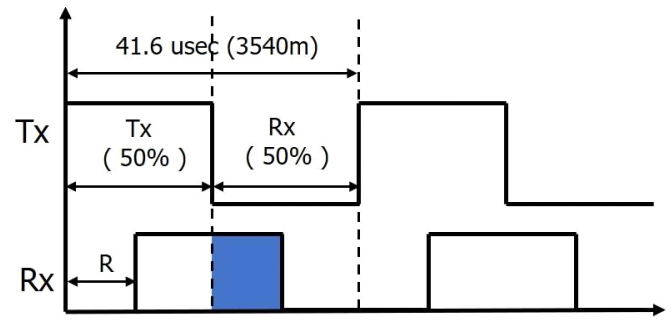

(a) $1,770 \mathrm{~m}$ 이내에서 수신된 신호

(a) Receive signal within $1,770 \mathrm{~m}$

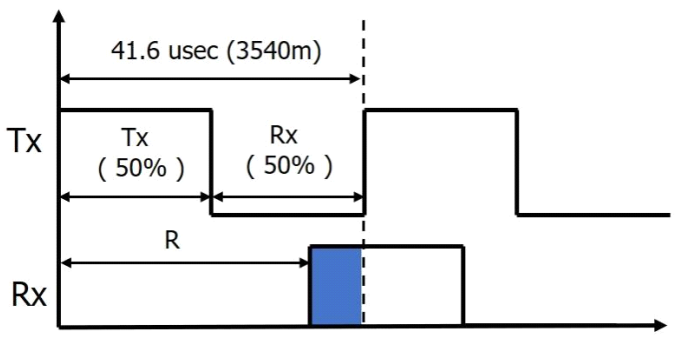

(b) $1,770 \mathrm{~m}$ 이상의 수신신호

(b) Receive signal over $1,770 \mathrm{~m}$

그림 6. 표적 거리에 따른 수신 신호

Fig. 6. Received signals by different ranges.

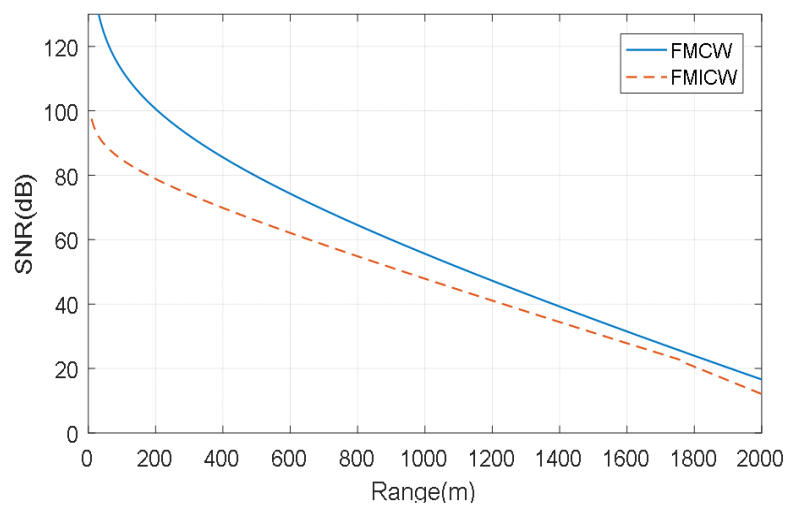

그림 7. 표적 거리에 따른 신호 대 잡음비의 비교 Fig. 7. Comparison of SNR.

되어야 할 것이다.

설계된 FMICW 신호로 2절에서와 동일한 그림 1의 과정 으로 몬테카를로 시뮬레이션을 수행하였으며 결과를 그림 8 에 나타내었다. 그림의 실선은 그림 2 와 동일한 $\mathrm{FMCW}$ 을 사용하였을 때의 $\mathrm{rms}$ 에러, 점선은 $\mathrm{FMICW}$ 의 $\mathrm{SNR}$ 감 소를 반영하여 계산된 $\mathrm{rms}$ 에러이다, $\mathrm{x}$ 표는 몬테카를로 


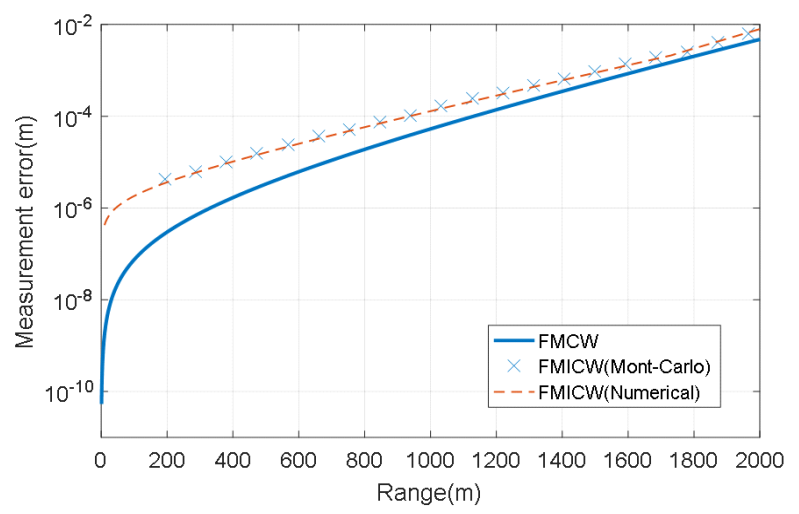

그림 8. 거리에 따른 RMS 오차의 비교

Fig. 8. Comparison of RMS error.

시뮬레이션을 수행한 결과로 계산된 값에 일치하는 것을 알 수 있다.

\section{V. 결 론}

본 논문은 지구 온난화에 의한 빙붕의 두께 변화를 레이 다로 측정하는 방식을 소개하고, 수신기의 동적 범위를 줄 이기 위한 FMICW 방식을 제안하였다. 기존의 FMCW 방 식에서는 표면과 바닥 반사 신호를 동시에 수신되기 때문에 $160 \mathrm{~dB}$ 이상의 수신기 동적 범위가 요구되었으나, 제안된 $\mathrm{FMICW}$ 방식에서는 두 신호가 시간적으로 분리되므로, STC(Sensitivity Time Control)을 사용하거나, 수신 구간을 변경하여 최소 탐지거리를 조정할 수 있다. $\mathrm{SNR}$ 을 기준으 로 한 디지털 변환기의 동적 범위도 $120 \mathrm{~dB}$ 에서 $90 \mathrm{~dB}$ 정도 로 줄어든다. 그러나 펄스 사용으로 인해 동일 피크파워 를 사용했을 때 SNR이 줄어드는 단점이 있으며, 이로 인 한 정확도의 손실은 가까운 거리에서 더 크게 나타난다.

\section{References}

[1] H. Han, S. Lee, J. I. Kim, S. H. Kim, and H. C. Kim, "Changes in a giant iceberg created from the collapse of the Larsen C Ice Shelf, Antarctic Peninsula, derived from Sentinel-1 and CryoSat-2 data," Remote Sensing, vol. 11, no. 4, p. 404, 2019.

[2] H. F. J. Corr, A. Jenkins, K. W. Nicholls, and C. S. M.
Doake, "Precise measurement of changes in ice-shelf thickness by phase-sensitive radar to determine basal melt rates," Geophysical Research Letters, vol. 29, no. 8, p. 73-1-74-4, 2002.

[3] P. V. Brennan, L. B. Lok, K. Nicholls, and H. Corr, "Phase-sensitive FMCW radar system for high-precision Antarctic ice shelf profile monitoring," IET Radar, Sonar and Navigation, vol. 8, no. 7, pp. 776-786, Aug. 2014.

[4] S. Rahman, "FMCW radar signal processing for antarctic ice shelf profiling and imaging," Ph.D. dissertation, University College London, London, UK, 2016.

[5] Q. Guoqing, "High accuracy range estimation of FMCW level radar based on the phase of the zero-padded FFT," in Proceedings 7th International Conference on Signal Processing 2004, Beijing, 2004, vol. 3, pp. 2078-2081.

[6] J. H. Lee, J. H. Jang, J. E. Roh, K. J. Yoo, and J. H. Choi, "Jamming detection and suppression algorithm for an FMCW radar altimeter," The Journal of Korean Institute of Electromagnetic Engineering and Science, vol. 27, no. 2, pp. 147-155, 2016.

[7] J. H. Hwang, S. H. Kim, K. M. Kang, and D. J. Kim, "Design and manufacture of FMCW radar with multifrequency bandwidths," The Journal of Korean Institute of Electromagnetic Engineering and Science, vol. 27, no. 4, pp. 377-387, 2016.

[8] J. H. Choi, J. H. Jang, J. H. Lee, and J. E. Roh, "Implementation of signal processing algorithms for an FMCW radar altimeter," The Journal of Korean Institute of Electromagnetic Engineering and Science, vol. 26, no. 6, pp. 555-563, 2016.

[9] E. G. Hyun, W. J. Oh, and J. H. Lee, "Simple method for improving the frequency sweep linearity of FMCW collision warning radar," The Journal of Korean Institute of Electromagnetic Engineering and Science, vol. 21, no. 10, pp. 1109-1115, 2010.

[10] B. R. Mahafza, Radar Systems Analysis and Design Using MATLAB, Boca Raton, FL, CRC Press, 2002. 
THE JOURNAL OF KOREAN INSTITUTE OF ELECTROMAGNETIC ENGINEERING AND SCIENCE. vol. 30, no. 12, Dec. 2019.

이 영 재 [세종대학교/석사과정]

https://orcid.org/0000-0001-5728-5279

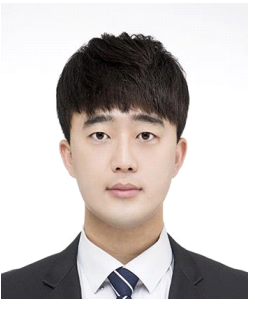

2018년 2월: 세종대학교 항공우주공학과 (공학사)

2018년 3월 현재: 세종대학교 국방시스템 공학과 레이다 및 전자전 전공 석사과정

[주 관심분야] 레이다, 신호처리, 시스템 설계
김 은 희[세종대학교 부교수]

https://orcid.org/0000-0001-5118-5509

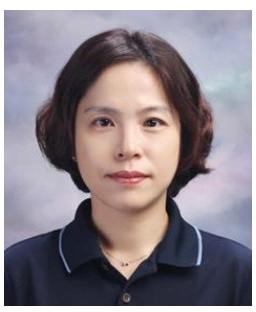

1999년 2월: 한국과학기술원 정밀공학과 (공학석사)

2004년 8월: 한국과학기술원 기계공학과 (공학박사)

2007년 10월: LIG넥스원, ISR연구센터 수 석연구원

2013년 9월 현재: 세종대학교 국방시스

템공학과 부교수

[주 관심분야] 레이다 신호처리, 레이다 시스템

신 승 하[(주)유텔/수석연구원]

https://orcid.org/0000-0001-9921-3142

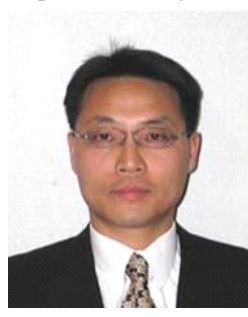

1992년 2월: 경희대학교 전자공학과(공학

사)

1994년 2월: 경희대학교 전자공학과(공학 석사)

2012년 2월: 경희대학교 전자공학과(공학 박사)

2013년 2월 현재: (주)유텔 수석연구원

[주 관심분야] $\mathrm{RF} / \mathrm{MW}$, 근거리 레이다 시스템, $\mathrm{SAR}, \mathrm{IPR} / \mathrm{GPR}$ 